\title{
Prognostic value of HE4 in patients with ovarian
} cancer

https://doi.org/10.1515/cclm-2017-1176

Received December 22, 2017; accepted January 2, 2018; previously published online February 8, 2018

\section{Abstract}

Background: There is no consensus in the medical community about the prognostic role of preoperative serum levels of human epididymis protein 4 (HE4) in ovarian cancer (OC). The purpose of this meta-analysis was to establish whether preoperative serum levels of HE4 are associated with $\mathrm{OC}$ prognosis.

Content: Eligible studies were searched for in PubMed, ClinicalTrials.gov, CNKI and Wanfang Med Online. We performed a meta-analysis of 1315 OC cases from 14 published articles.

Summary: Our meta-analysis demonstrated that high HE4 was associated with poor overall survival (OS) (random effects model, hazard ratio $[\mathrm{HR}]=1.91,95 \%$ confidence interval $\left.[\mathrm{CI}]=1.40-2.614, \mathrm{p}<0.0001 ; \mathrm{I}^{2}=52 \%, \mathrm{p}=0.04\right)$ and; progression-free survival (PFS) (random effects model, $\left.\mathrm{HR}=1.38,95 \% \mathrm{CI}=1.13-1.69, \mathrm{p}=0.002 ; \mathrm{I}^{2}=85 \%, \mathrm{p}<0.00001\right)$. However, subgroup analysis showed that high HE4 was not associated with poor OS (fixed effects model, $\mathrm{HR}=1.86,95 \%$ $\mathrm{CI}=0.89-3.89, \mathrm{p}=0.1 ; \mathrm{I}^{2}=34 \%, \mathrm{p}=0.22$ ) or PFS (random effects model, $\mathrm{HR}=1.34,95 \% \mathrm{CI}=0.95-1.88, \mathrm{p}=0.1 ; \mathrm{I}^{2}=69 \%$, $\mathrm{p}=0.007$ ) for studies including only Asian populations.

Outlook: In conclusion, this meta-analysis shows that high HE4 was associated with poor OC OS and PFS overall. However, the association of high HE4 with poor OS and PFS was not observed for Asians. Large-scale, multicenter investigations should be performed.

\footnotetext{
*Corresponding authors: Prof. Shi Yan, MD and Prof. Beihua Kong, MD, Department of Obstetrics and Gynecology, and Gynecologic Oncology Key Laboratory of Shandong Province, Qilu Hospital of Shandong University, Ji’nan, P.R. China, E-mail: gggg2182@126.com (S. Yan); kongbeihua@sdu.edu.cn (B. Kong)

Cunzhong Yuan: Shenzhen Research Institute of Shandong University, Shenzhen, China. http://orcid.org/0000-00028785-2139; and Department of Obstetrics and Gynecology, and Gynecologic Oncology Key Laboratory of Shandong Province, Qilu Hospital of Shandong University, Ji'nan, P.R. China Rongrong Li: Department of Obstetrics and Gynecology, and Gynecologic Oncology Key Laboratory of Shandong Province, Qilu Hospital of Shandong University, Ji'nan, P.R. China
}

Keywords: HE4; meta-analysis; ovarian cancer; prognosis.

\section{Introduction}

Epithelial ovarian cancer (EOC) is the fourth most common cause of female cancer death and the leading cause of death from gynecologic cancer in the developed world [1], with over 22,440 new cases and 14,080 deaths in the United States in 2017 [2]. Even with numerous efforts to improve surgical techniques and with carefully designed chemotherapy programs, the 5-year survival rate remains $10 \%-30 \%$ [3-6]. The poor rate of survival and the high rate of lethality are primarily due to late detection and rapid progression [3-6]. Therefore, there is an urgent need to find reliable predictive biomarkers of patients' prognosis and to develop novel therapeutic strategies [6].

Carbohydrate antigen 125 (CA125) levels are widely used for the diagnosis of ovarian cancer (OC). Unfortunately, because of its high false-positive and false-negative rates, CA125 has a limited value for prognosis. The human epididymis protein 4 (HE4) is located on chromosome 20q12-13; HE4 is encoded by the WFDC2 gene, which is one of several WAP domain-coding genes within that chromosomal region [7, 8]. HE4 is highly expressed in different types of OC, especially in serous and endometrioid cancers [9]. HE4 has been used in EOC diagnosis [10]. In 2008, HE4 was the first biomarker since CA125 to be approved by the FDA for monitoring patients with OC for disease recurrence [11]. In particular, the combination of HE4 and CA125 (ROMA algorithm) has been recommended for differential diagnosis of OC in patients with pelvic masses [12].

However, there is no consensus in the medical community about the prognostic role of preoperative serum levels of HE4 in OC. Some studies have evaluated the role of HE4 as a prognostic factor of $\mathrm{OC}[8,13-25]$, but the experimental results remain inconclusive. A few previous studies have been limited by their relatively small patient populations. To systematically evaluate the potential of preoperative serum levels of HE4 as a biomarker for the prognostic prediction of OC, we conducted a meta-analysis. 


\section{Materials and methods}

\section{Search and selection process}

We performed this meta-analysis by following the Preferred Reporting Items for Systematic Reviews and MetaAnalyses (PRISMA) criteria (Checklist S1) [26].

We searched the PubMed database, ClinicalTrials.gov, China National Knowledge Infrastructure (CNKI) database and Wanfang Med Online, using combinations of the following keywords: ("HE4" or "human epididymis secretory protein E4" or "human epididymis protein 4") and ("tumor" or "cancer" or "carcinoma" or "neoplasm" or "malignancy") and ("ovarian” or "ovary") and ("survival" or "outcome" "prognosis" or "prognostic" or "mortality") from January 1, 2000, to May 20, 2017. Two authors, Yan and $\mathrm{Li}$, independently examined the retrieved references to assess their appropriateness for inclusion in this metaanalysis. In addition, we investigated all of the relevant literature cited in the articles and reviews.

\section{Selection criteria and quality score assessment}

Studies were required to meet the following criteria: (a) the association of HE4 with the prognostic value in OC should be described; (b) the studies reported survival outcomes (overall survival [OS], progression-free

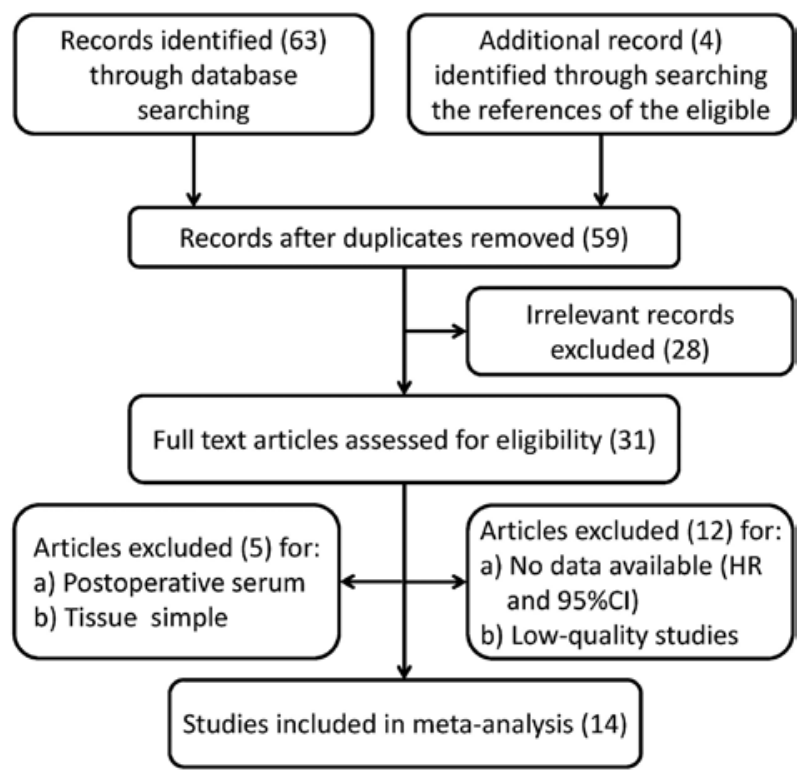

Figure 1: Study flowchart outlining the selection of the studies included in the meta-analysis. survival [PFS] or disease-free survival [DFS]) with HR and $95 \%$ CI or survival curves; and (c) the studies were published in the English literature or Chinese literature. The exclusion criteria were no sufficient data for obtaining hazard ratio (HR) and 95\% confidence interval (CI).

All studies were independently evaluated by the two authors (Yan and Li) according to a critical review checklist of the Dutch Cochrane Centre proposed by MOOSE [27, 28]. The key points of the current checklist include the following: (a) clear definition of the study population and origin of country; (b) clear definition of the association of HE4 with the prognostic value in OC; (c) clear definition of the study design; (d) clear definition of the outcome assessment; (e) clear definition of the measurement of HE4; (f) clear definition of the cutoff of HE4; and (g) sufficient period of follow-up. The 14 studies included mentioned all seven points $[27,28]$. A flow diagram of the study selection process is presented in Figure 1.

\section{Data extraction}

The data of the eligible studies were independently extracted according to the prespecified criteria by the two authors (Yan and Li). Inconsistencies in data extraction were resolved by joint review and consensus. All of the necessary information, if available, was extracted from each study, including first author, publication year, period of patient recruitment, country, institution of the patients, ethnicity, cancer type, case no., HE4 high no., HE4 low no., sample type, test methods, reagent brand, age (years), cutoff values and follow-up (Table 1). In addition, the HRs of HE4 expression for OS, PFS or DFS and 95\% CIs were extracted (Table 2). If the HRs and 95\% CIs were not directly available, we calculated HRs and their 95\% CIs from survival curves by the methods reported by Tierney et al. [29, 30].

\section{Statistical analysis}

Pooled HRs and 95\% CIs were used to evaluate the association of HE4 with OC prognosis. The multivariate Cox model was the most appropriate method for OS and PFS, but a univariate Cox model was chosen when the multivariate Cox model was not available. We calculated HRs and their 95\% CIs from survival curves using a univariate Cox model. An observed HR of more than one indicated a poorer prognosis for patients with high HE4 than for those with low HE4. A heterogeneity test of pooled HR was calculated using Cochran's Q test and Higgins 


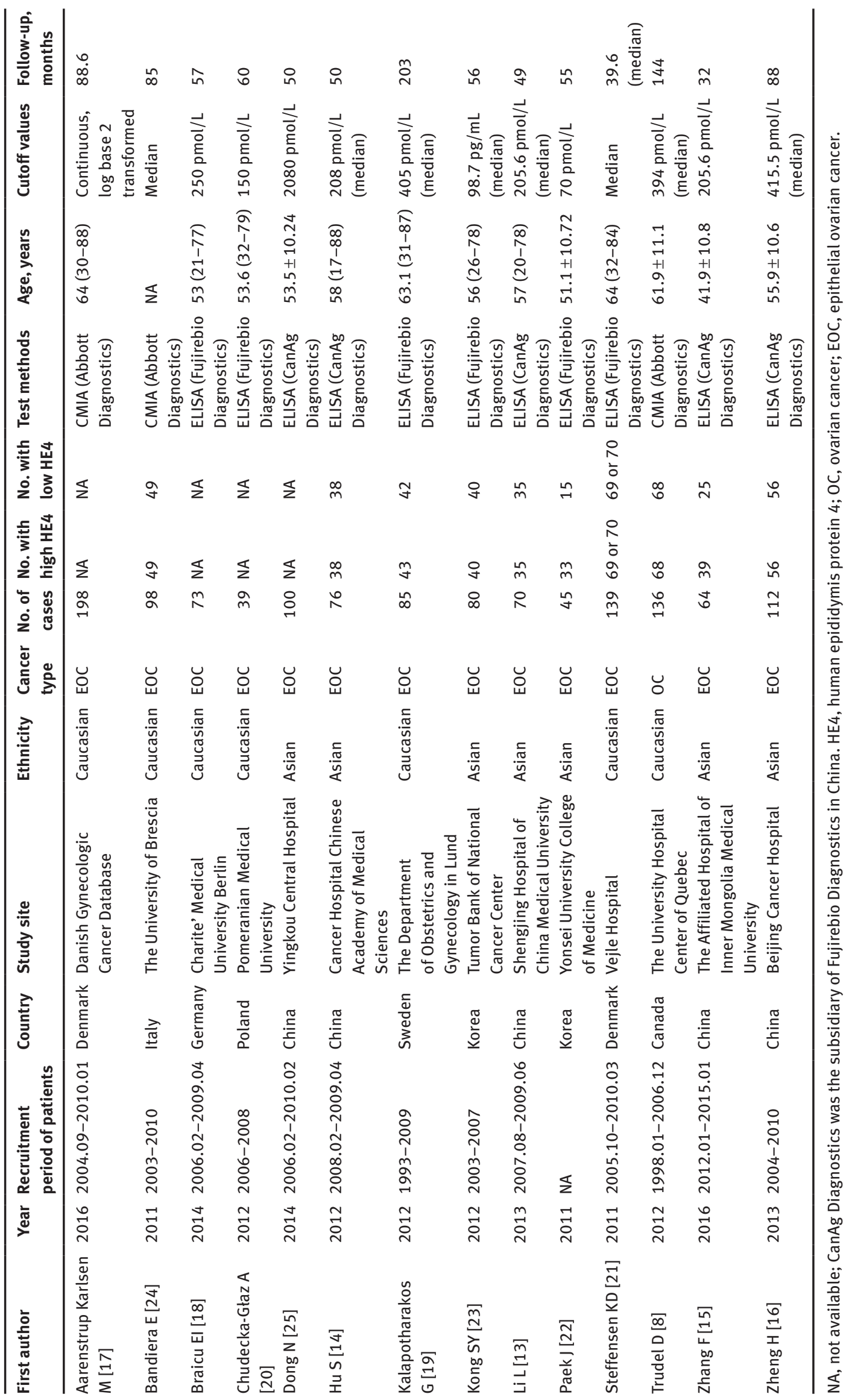




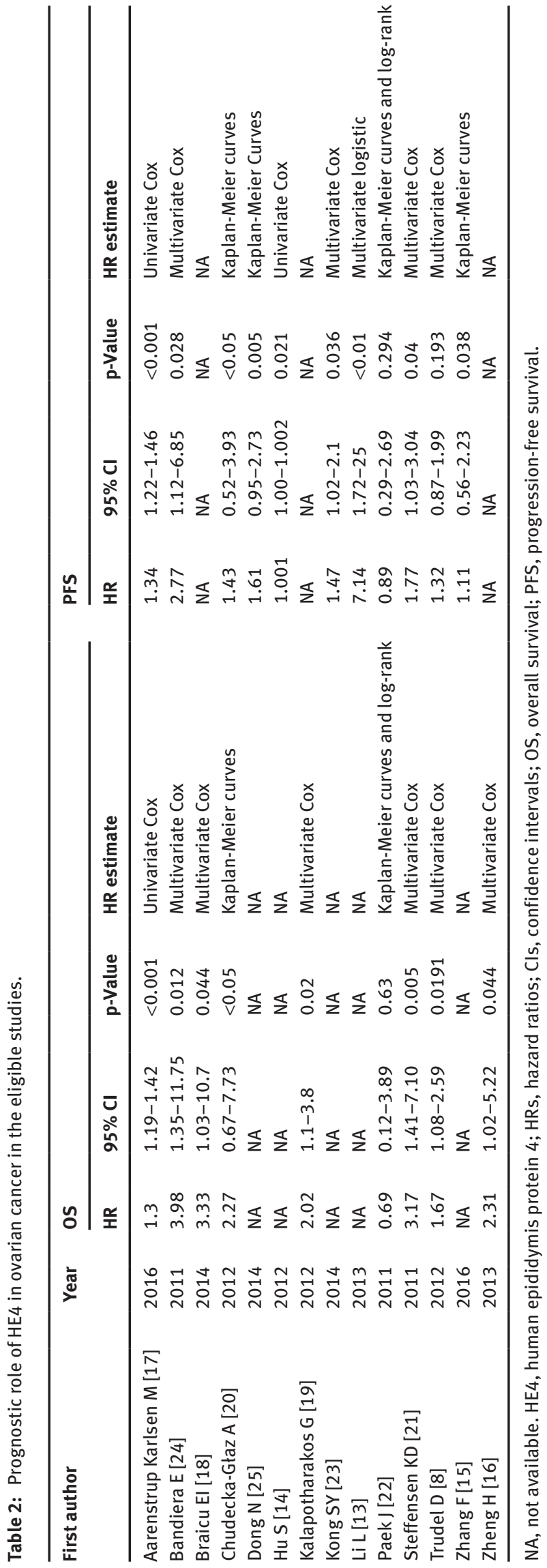

$\mathrm{I}^{2}$ statistic [31]. If the heterogeneity was significant, a random effects model was used; otherwise, a fixed effects model was chosen [32, 33]. In addition, a sensitivity analysis was performed by omitting each study. Furthermore, subgroup analysis stratified by ethnicity, HR estimate method and test methods was also performed. Publication bias was examined using a funnel plot. The degree of asymmetry was estimated by Egger's test $(p<0.05$ was considered to indicate significant publication bias) [34, 35]. The statistical analyses were performed using Review Manager statistical software (RevMan version 5.0.17.0; The Nordic Cochrane Center, Rigs Hospitalet, Copenhagen, Denmark) and STATA software (version 11.2; Stata Corporation, College Station, TX, USA). A p-value of $<0.05$ was considered statistically significant.

\section{Results}

\section{Search results}

Through the article search, we found 59 articles. We excluded 28 because the studies were irrelevant. We also excluded 12 articles because no data were available (HR and 95\% CI), no data were also calculated from survival curves or the data were of low quality. Five articles were excluded because of a lack of preoperative serum samples.

A total of 14 articles [8, 13-25] published from 2011 to 2016 with 1315 patients satisfied the criteria for the meta-analysis. The flowchart of the study is shown in Figure 1 . There were nine articles $[8,17-24]$ published in English and five articles [13-16, 25] published in Chinese.

\section{Characteristics of studies}

The characteristics of the 14 studies are summarized in Tables 1 and 2. The subjects in seven of the studies were Asian [13-16, 22, 23, 25], and the subjects in the other studies were Caucasian [8, 17-21, 24]. Most of the patients in these studies were diagnosed with EOC with different tumor types. The sample type in 14 studies was preoperative serum; 9 studies $[8,16-22,24]$ were conducted to investigate OS, and 11 studies [8, 13-15, 17, 20-25] were performed to analyze PFS. HE4 levels were tested by ELISA in 11 studies [13-16, 18-23, 25] and by CMIA in three studies $[8,17,24]$. 


\section{OS}

\begin{tabular}{|c|c|c|c|c|c|c|c|c|}
\hline Study or subgroup & log[Hazard ratio] & SE & Weight & $\begin{array}{l}\text { Hazard ratio } \\
\text { IV. Random. } 95 \% \mathrm{Cl}\end{array}$ & & $\begin{array}{r}\text { Hazar } \\
\text { IV. Rand }\end{array}$ & $\begin{array}{l}\text { d ratio } \\
\text { om. } 95 \% \mathrm{Cl}\end{array}$ & \\
\hline Aarenstrup K M 2016 & 0.262 & 0.045 & $28.3 \%$ & $1.30[1.19,1.42]$ & & & E & \\
\hline Bandiera E 2011 & 1.381 & 0.552 & $6.5 \%$ & $3.98[1.35,11.74]$ & & & & \\
\hline Braicu El 2014 & 1.203 & 0.597 & $5.7 \%$ & $3.33[1.03,10.73]$ & & & & \\
\hline Chudecka-Głaz A 2012 & 0.82 & 0.652 & $5.0 \%$ & $2.27[0.63,8.15]$ & & & & \\
\hline Kalapotharakos G 2012 & 0.703 & 0.316 & $13.5 \%$ & $2.02[1.09,3.75]$ & & & 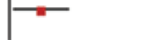 & \\
\hline Paek J 2011 & -0.371 & 0.887 & $2.9 \%$ & $0.69[0.12,3.93]$ & & & & \\
\hline Steffensen KD 2011 & 1.154 & 0.412 & $9.9 \%$ & $3.17[1.41,7.11]$ & & & $\longrightarrow$ & \\
\hline Trudel D 2012 & 0.513 & 0.223 & $18.5 \%$ & $1.67[1.08,2.59]$ & & & 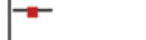 & \\
\hline Zheng H 2013 & 0.837 & 0.417 & $9.7 \%$ & $2.31[1.02,5.23]$ & & & & \\
\hline Total $(95 \% \mathrm{Cl})$ & & & $100.0 \%$ & $1.91[1.40,2.61]$ & & & & \\
\hline \multicolumn{4}{|c|}{$\begin{array}{l}\text { Heterogeneity: } \tau^{2}=0.09 ; \chi^{2}=16.51, d f=8(p=0.04) ; 1^{2}=52 \% \\
\text { Test for overall effect: } Z=4.06(p<0.0001)\end{array}$} & & 0.01 & $\begin{array}{l}0.1 \\
\text { HE4 High }\end{array}$ & ${ }^{1} \begin{array}{r}10 \\
\text { HE4 Low }\end{array}$ & 100 \\
\hline
\end{tabular}

\section{PFS}

\begin{tabular}{|c|c|c|c|c|c|c|c|c|}
\hline Study or subgroup & log[Hazard ratio] & SE & Weight & $\begin{array}{c}\text { Hazard ratio } \\
\text { IV. Random, } 95 \% \mathrm{Cl}\end{array}$ & & $\begin{array}{r}\text { Hazard } \\
\text { IV. Randor }\end{array}$ & $\begin{array}{l}\text { d ratio } \\
\text { m. } 95 \% \mathrm{Cl}\end{array}$ & \\
\hline Aarenstrup K M 2016 & 0.293 & 0.046 & $20.2 \%$ & $1.34[1.22,1.47]$ & & & $=$ & \\
\hline Bandiera E 2011 & 1.019 & 0.462 & $4.0 \%$ & $2.77[1.12,6.85]$ & & & & \\
\hline Chudecka-Głaz A 2012 & 0.358 & 0.516 & $3.3 \%$ & $1.43[0.52,3.93]$ & & & & \\
\hline Dong N 2014 & 0.476 & 0.269 & $8.6 \%$ & $1.61[0.95,2.73]$ & & & - & \\
\hline Hu S 2012 & 0.001 & 0.001 & $21.0 \%$ & $1.00[1.00,1.00]$ & & & & \\
\hline Kong SY 2014 & 0.385 & 0.184 & $12.5 \%$ & $1.47[1.02,2.11]$ & & & - & \\
\hline Li L 2013 & 1.966 & 0.683 & $2.0 \%$ & $7.14[1.87,27.24]$ & & & & \\
\hline Paek J 2011 & -0.117 & 0.568 & $2.8 \%$ & $0.89[0.29,2.71]$ & & & & \\
\hline Steffensen KD 2011 & 0.571 & 0.276 & $8.3 \%$ & $1.77[1.03,3.04]$ & & & $=$ & \\
\hline Trudel D 2012 & 0.278 & 0.211 & $11.1 \%$ & $1.32[0.87,2.00]$ & & & $=$ & \\
\hline Zhang F 2016 & 0.104 & 0.353 & $6.0 \%$ & $1.11[0.56,2.22]$ & & & $\leftarrow$ & \\
\hline Total $(95 \% \mathrm{Cl})$ & & & $100.0 \%$ & $1.38[1.13,1.69]$ & & & $\bullet$ & \\
\hline \multicolumn{5}{|c|}{$\begin{array}{l}\text { Heterogeneity: } \tau^{2}=0.05 ; \chi^{2}=67.46, d f=10(p<0.00001) ; l^{2}=85 \% \\
\text { Test for overall effect: } Z=3.14(p=0.002)\end{array}$} & 0.01 & $\begin{array}{c}0.1 \\
\mathrm{HE} 4 \mathrm{HIGH}\end{array}$ & ${ }^{1} \begin{array}{c}10 \\
\text { HE4 LOW }\end{array}$ & 100 \\
\hline
\end{tabular}

Figure 2: Forest plot summary of the HRs and $95 \% \mathrm{Cls}$ for the association between HE4 and ovarian cancer prognosis.

\section{Meta-analysis}

The meta-analysis results regarding HE4 are shown in Figure 2. Our meta-analysis demonstrated that high HE4 was associated with poor OS (random effects model, $\mathrm{HR}=1.91, \quad 95 \% \quad \mathrm{CI}=1.40-2.614, \quad \mathrm{p}<0.0001 ; \quad \mathrm{I}^{2}=52 \%$, $\mathrm{p}=0.04$ ) and poor PFS (random effects model, $\mathrm{HR}=1.38$, 95\% CI $\left.=1.13-1.69, \mathrm{p}=0.002 ; \mathrm{I}^{2}=85 \%, \mathrm{p}<0.00001\right)$.

Furthermore, a subgroup analysis stratified by ethnicity, HR estimate method and test methods was also performed (Table 3). The associations of high HE4 with poor OS (random effects model, $\mathrm{HR}=1.96,95 \% \mathrm{CI}=1.39-2.77$, $\mathrm{p}=0.0001 ; \mathrm{I}^{2}=58 \%, \mathrm{p}=0.03$ ) and poor PFS (fixed effects model, HR=1.36, 95\% CI =1.25-1.48, $\mathrm{p}<0.00001 ; \mathrm{I}^{2}=0 \%$, $\mathrm{p}=0.49$ ) were observed for studies including only Caucasian patients. However, the associations of high HE4 with poor OS (fixed effects model, $\mathrm{HR}=1.86,95 \% \mathrm{CI}=0.89-3.89$, $\mathrm{p}=0.1 ; \mathrm{I}^{2}=34 \%, \mathrm{p}=0.22$ ) and poor PFS (random effects model, $\mathrm{HR}=1.34,95 \% \mathrm{CI}=0.95-1.88, \mathrm{p}=0.1 ; \mathrm{I}^{2}=69 \%$, $\mathrm{p}=0.007$ ) were not observed for studies including only Asian patients.

Subsequently, the association of high HE4 with poor OS was observed for studies using multivariate Cox and univariate Cox analyses $(\mathrm{HR}=2.16,95 \% \mathrm{CI}=1.63-2.87$, $\mathrm{p}<0.00001 ; \mathrm{I}^{2}=0 \%, \mathrm{p}=0.55$ and $\mathrm{HR}=1.3,95 \% \mathrm{CI}=1.19-$ $1.42, \mathrm{p}<0.00001 ; \mathrm{I}^{2}=0 \%, \mathrm{p}=0.54$, respectively) both with fixed effects models. There was no association between high HE4 and poor PFS for studies using univariate Cox analysis (random effects model, $\mathrm{HR}=1.2,95 \% \mathrm{CI}=0.95-$ $\left.1.51, \mathrm{p}=0.13 ; \mathrm{I}^{2}=89 \%, \mathrm{p}<0.00001\right)$. There was an association between high HE4 and poor PFS in studies using a multivariate Cox model (fixed effects model, $H R=1.61$, $95 \% \mathrm{CI}=1.27-2.02, \mathrm{p}<0.0001 ; \mathrm{I}^{2}=46 \%, \mathrm{p}=0.12$ ).

The association of high HE4 with poor OS was observed, both with fixed effects models, when HE4 was measured by CMIA and ELISA ( $\mathrm{HR}=1.32,95 \% \mathrm{CI}=1.21-$ 1.44, $\mathrm{p}<0.00001 ; \mathrm{I}^{2}=62 \%, \mathrm{p}=0.07$ and $\mathrm{HR}=2.31,95 \%$ $\mathrm{CI}=1.59-3.34, \mathrm{p}<0.00001 ; \mathrm{I}^{2}=0 \%, \mathrm{p}=0.7$, respectively). 


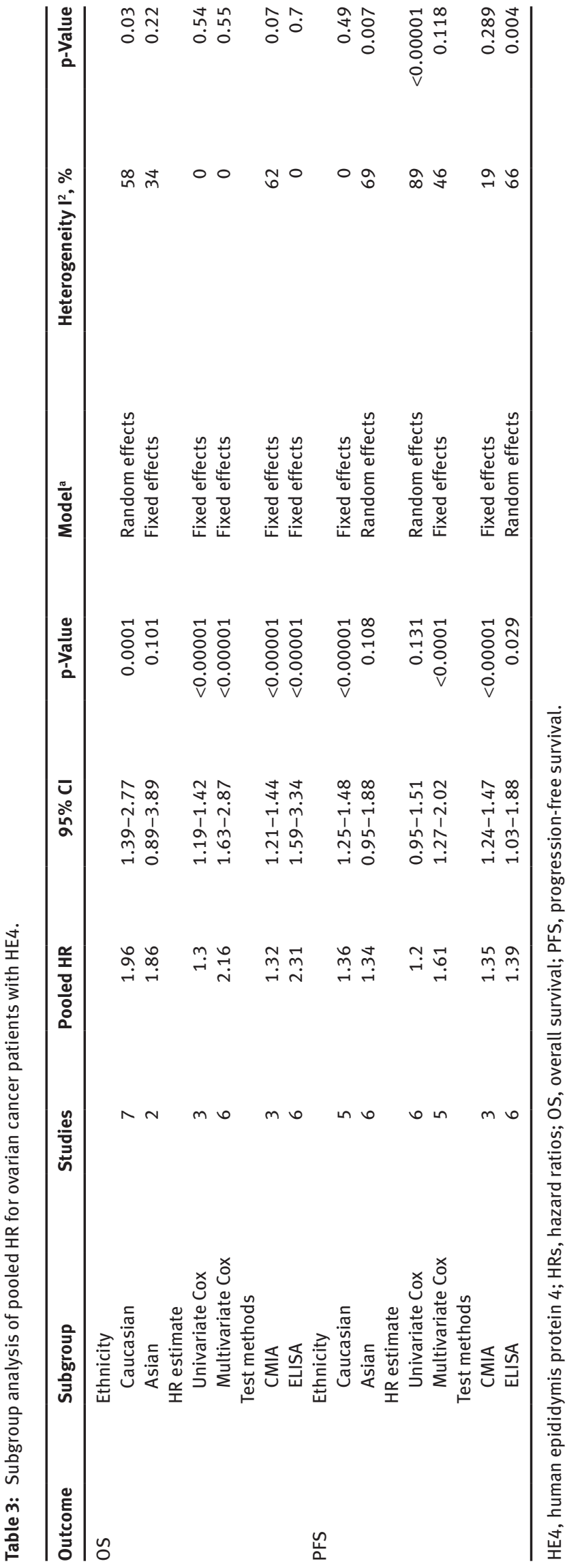

There was an association between high HE4 with poor PFS when HE4 was measured by CMIA (fixed effects model, HR=1.35, 95\% CI =1.24-1.47, $\mathrm{p}<0.00001 ; \mathrm{I}^{2}=19 \%$, $\mathrm{p}=0.29$ ). There was no association between high HE 4 with poor PFS when HE4 was measured by ELISA (random effects model, $\mathrm{HR}=1.39,95 \% \mathrm{CI}=1.03-1.88, \mathrm{p}=0.03$; $\left.I^{2}=66 \%, p=0.004\right)$.

\section{Sensitivity analysis and publication bias}

A statistical significant heterogeneity was found among studies evaluating the association between HE4 and both OS and PFS ( $p=0.04$ and $p<0.00001$, respectively). Therefore, a random effects model was applied to assess the pooled HR and its 95\% CI. A sensitivity analysis was carried out by sequential omission of individual studies. The pooled HRs of OS and DFS were not significantly changed, suggesting the robustness of the results.

We checked the publication bias using both Begg's funnel plot and Egger's test. The shapes of the two Begg's funnel plots for all studies showed no obvious asymmetry (Figure 3). Egger's test of all studies showed no significant publication bias for OS or PFS (data not shown).

\section{Discussion}

HE4 is highly expressed in OC [9]. HE4 has been used in OC diagnosis. A combination of HE4 and CA125, as well as ultrasound imaging, has been used to diagnose EOC, but there are no satisfactory molecular markers for the prognostic prediction of OC in clinical practice. Some studies have begun to explore the prognostic role of HE4 for OC [8, 13-25, 36]; however, results have been inconsistent. The aim of this study was to conduct a systematic review to evaluate the accuracy of serum HE4 as a prognostic biomarker for OC, a disease with high mortality.

Scaletta et al. [37] reviewed that serum HE4 seems to have a promising role in the prediction of clinical and surgical outcomes. We completed the meta-analysis to further calculate preoperative serum levels of HE4 as a marker for OC prognosis. This meta-analysis shows that high HE4 was associated with poor prognosis in the studies evaluated. HE 4 was a probable effective biomarker for OC prognosis.

Of the 14 included studies, 4 [20, 22, 25, 38] did not have directly available HR and 95\% CI values; thus, we calculated the HRs and their 95\% CIs from the survival curves. The HRs from the survival curves were generated using a univariate Cox model, and there was also a study 

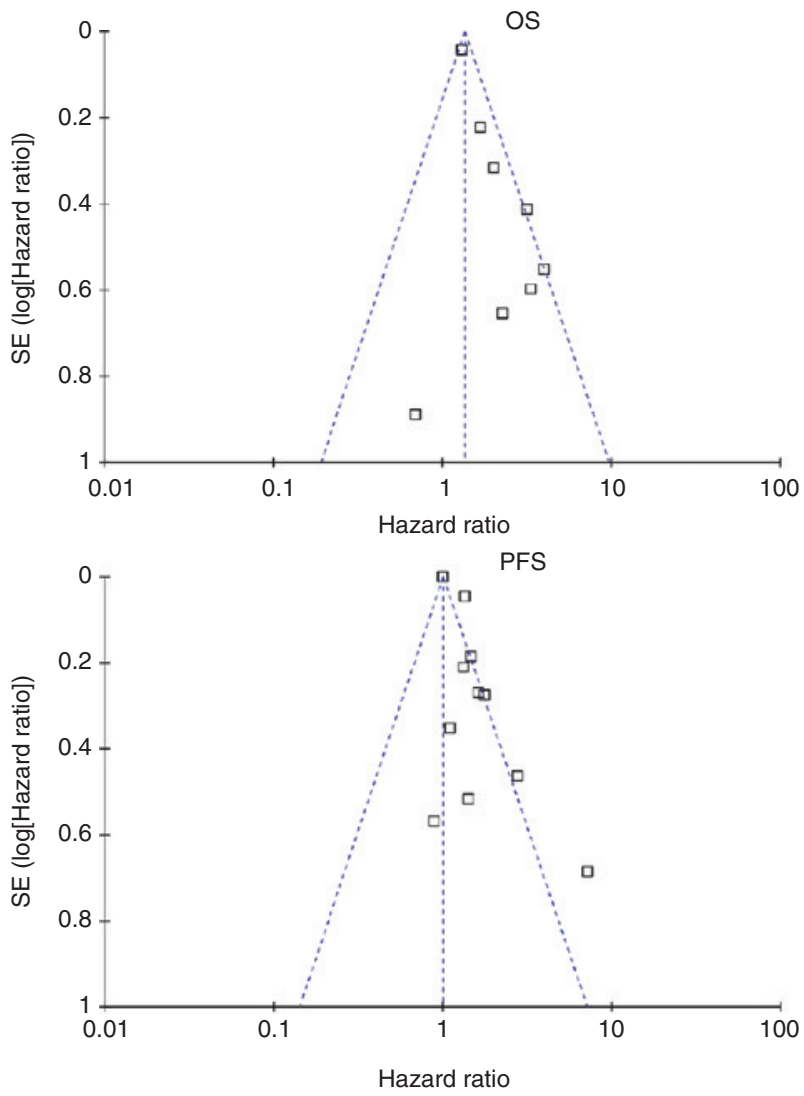

Figure 3: Begg's funnel plot of HE4 and ovarian cancer prognosis for all 14 studies.

in which the HRs and their $95 \% \mathrm{CI}$ were based on a univariate Cox model [17]. Therefore, there were studies based on both a univariate Cox model and a multivariate Cox model. Perhaps this result was the one of the reasons contributing to the heterogeneity in the meta-analysis. The subgroup analysis showed that there was no heterogeneity in the evaluations of OS based on multivariate Cox and univariate Cox models. However, the heterogeneity was significant for PFS assessed by univariate Cox analysis, suggesting that the HR estimation methods were important and that these methods may have affected the result.

There were two ethnicities (Caucasian and Asian) in the 14 studies included in the meta-analysis. The association of high HE4 with poor OS and poor PFS was observed only for Caucasians. Ethnicity probably contributed to this difference in association. In general, multicenter studies can provide more valuable conclusions than single-center studies [33]. Although high HE4 was associated with poor OC prognosis, the larger sample studies of HE4 and OC prognosis should be done. Multicenter studies are sure more valuable. For some molecular markers for diagnosis and prognosis, there are differences between different ethnic group and region. Large-scale, singlecenter studies are also valuable. This type of stratification was one of the differences between this study and others [33].

The cutoff used in the 14 studies were very different. The median values of the seven studies were regarded as cutoff values. Did the differences of HE4 in the studies affect the HE4 and OC prognosis? It needs to be studied further. In addition, the role for HE4 in cell growth and OC progression was rarely studied. It should also be studied to better understand HE4 and OC.

This meta-analysis has objectively and systematically calculated the association between preoperative serum levels of HE4 and OC prognosis. The current studies have shown that HE4 was a probable effective biomarker for OC prognosis. However, more large-scale, multicenter investigations should be performed to testify the clinically applicable value of HE4.

In the past years, a wide spectrum of serological biomarkers for OC diagnosis and prognosis has been investigated. In addition to HE4, circulating micro-RNAs have also shown the potential clinical utility. However, a perfect and reliable biomarker (stable, highly specific and sensitive, inexpensive) is currently unavailable $[39,40]$. These molecules are needed to verify diagnostic performance and have great potential.

In conclusion, this meta-analysis shows that high HE4 was generally associated with OC, poor OS and PFS. HE4 was a probable effective biomarker for OC prognosis. However, the associations of high HE4 with poor OS and poor PFS were not observed for Asians. Larger scale and different ethnic investigations should be performed.

Author contributions: $\mathrm{CY}$ and BK conceived and designed the experiments. SY and RL examined articles. CY and SY analyzed the data. CY wrote the paper. All the authors have accepted responsibility for the entire content and approved the submission of this manuscript.

Research funding: This work was supported by the Shenzhenfutureindustryspecialfund(JCYJ20150403104645648), the Natural Science Foundation of Shandong Province (ZR2016HM38, ZR2014HM070, BS2014SW009, and ZR2016HM02), the National Natural Science Foundation of China (81572554, 31501501), the Foundation of Shandong Public Health Department (2014WS0123, 2014WS0134) and the National Clinical Research Center for Gynecological Oncology (2015BAI13B05). The funders had no role in the study design, data collection and analysis, decision to publish or preparation of the manuscript.

Employment or leadership: None declared.

Honorarium: None declared. 
Competing interests: The funding organization(s) played no role in the study design; in the collection, analysis, and interpretation of data; in the writing of the report; or in the decision to submit the report for publication.

\section{References}

1. Jayson GC, Kohn EC, Kitchener HC, Ledermann JA. Ovarian cancer. Lancet 2014;384:1376-88.

2. Siegel RL, Miller KD, Jemal A. Cancer statistics, 2017. CA Cancer J Clin 2017;67:7-30.

3. Wei W, Li N, Sun Y, Li B, Xu L, Wu L. Clinical outcome and prognostic factors of patients with early-stage epithelial ovarian cancer. Oncotarget 2017;8:23862-70.

4. Jonsson JM, Skovbjerg Arildsen N, Malander S, Masback A, Hartman L, Nilbert M, et al. Sex steroid hormone receptor expression affects ovarian cancer survival. Transl Oncol 2015;8:424-33.

5. Liew PL, Hsu CS, Liu WM, Lee YC, Lee YC, Chen CL. Prognostic and predictive values of nrf2, keap1, p16 and e-cadherin expression in ovarian epithelial carcinoma. Int J Clin Exp Pathol 2015;8:5642-9.

6. Shen Z, Luo H, Li S, Sheng B, Zhao M, Zhu H, et al. Correlation between estrogen receptor expression and prognosis in epithelial ovarian cancer: a meta-analysis. Oncotarget 2017;8:62400-13.

7. Clauss A, Lilja H, Lundwall A. A locus on human chromosome 20 contains several genes expressing protease inhibitor domains with homology to whey acidic protein. Biochem J 2002;368:233-42.

8. Trudel D, Tetu B, Gregoire J, Plante M, Renaud MC, Bachvarov $D$, et al. Human epididymis protein 4 (he4) and ovarian cancer prognosis. Gynecol Oncol 2012;127:511-5.

9. Drapkin R, von Horsten HH, Lin Y, Mok SC, Crum CP, Welch WR, et al. Human epididymis protein 4 (he4) is a secreted glycoprotein that is overexpressed by serous and endometrioid ovarian carcinomas. Cancer Res 2005;65:2162-9.

10. Montagnana M, Danese E, Giudici S, Franchi M, Guidi GC, Plebani M, et al. He4 in ovarian cancer: from discovery to clinical application. Adv Clin Chem 2011;55:1-20.

11. Jia MM, Deng J, Cheng XL, Yan Z, Li QC, Xing YY, et al. Diagnostic accuracy of urine he 4 in patients with ovarian cancer: a metaanalysis. Oncotarget 2017;8:9660-71.

12. Moore RG, McMeekin DS, Brown AK, DiSilvestro P, Miller MC, Allard WJ, et al. A novel multiple marker bioassay utilizing he4 and ca125 for the prediction of ovarian cancer in patients with a pelvic mass. Gynecol Oncol 2009;112:40-6.

13. Li L, Wang R, Zhou X. Analysis of correlation between serum level of ca125 and he 4 and severity of ovarian cancer. Chin J Lab Diag 2013;17:829-32.

14. Hu S, Wang M, Gao J, Qi J. The clinical value of serum he4 for prognosis evaluation in patients with ovarian cancer. China Cancer 2012;21:638-40.

15. Zhang F. Correlation between serum he 4 and ca125 levels in diagnosis and prognosis of ovarian cancer. The Medical Forum 2016;20:503-4.
16. Zheng H, Gao Y, Gao WJ, Gao M, Yan X. Expression of serum human epididymis protein 4 in epithelial ovarian cancer and its correlation with prognosis. Chin J Oncol 2013;36:445-9.

17. Aarenstrup Karlsen M, Hogdall C, Nedergaard L, Philipsen Prahm K, Schou Karlsen NM, Weng Ekmann-Gade A, et al. He4 as a predictor of adjuvant chemotherapy resistance and survival in patients with epithelial ovarian cancer. APMIS 2016;124:1038-45.

18. Braicu El, Chekerov R, Richter R, Pop C, Nassir M, Loefgren H, et al. He4 expression in plasma correlates with surgical outcome and overall survival in patients with first ovarian cancer relapse. Ann Surg Oncol 2014;21:955-62.

19. Kalapotharakos G, Asciutto C, Henic E, Casslen B, Borgfeldt C. High preoperative blood levels of he4 predicts poor prognosis in patients with ovarian cancer. J Ovarian Res 2012;5:20.

20. Chudecka-Glaz A, Rzepka-Gorska I, Wojciechowska I. Human epididymal protein 4 (he4) is a novel biomarker and a promising prognostic factor in ovarian cancer patients. Eur J Gynaecol Oncol 2012;33:382-90.

21. Steffensen KD, Waldstrom M, Brandslund I, Jakobsen A. Prognostic impact of prechemotherapy serum levels of her2, ca125, and he4 in ovarian cancer patients. Int J Gynecol Cancer 2011;21:1040-7.

22. Paek J, Lee SH, Yim GW, Lee M, Kim YJ, Nam EJ, et al. Prognostic significance of human epididymis protein 4 in epithelial ovarian cancer. Eur J Obstet Gynecol Reprod Biol 2011;158:338-42.

23. Kong SY, Han MH, Yoo HJ, Hwang JH, Lim MC, Seo SS, et al. Serum he4 level is an independent prognostic factor in epithelial ovarian cancer. Ann Surg Oncol 2012;19:1707-12.

24. Bandiera E, Romani C, Specchia C, Zanotti L, Galli C, Ruggeri G, et al. Serum human epididymis protein 4 and risk for ovarian malignancy algorithm as new diagnostic and prognostic tools for epithelial ovarian cancer management. Cancer Epidemiol Biomarkers Prev 2011;20:2496-506.

25. Dong N. Study on the relationship between serum he4 level and prognosis of ovarian epithelial cancer patients. Guide of China Medicine 2014;12:235-6.

26. Moher D, Liberati A, Tetzlaff J, Altman DG, Group P. Preferred reporting items for systematic reviews and meta-analyses: the PRISMA statement. PLoS Med 2009;6:e1000097.

27. Stroup DF, Berlin JA, Morton SC, Olkin I, Williamson GD, Rennie $D$, et al. Meta-analysis of observational studies in epidemiology: a proposal for reporting. Meta-analysis of observational studies in epidemiology (moose) group. Am J Med Assoc 2000;283:2008-12.

28. Wang W, Li J, Zhu W, Gao C, Jiang R, Li W, et al. Microrna-21 and the clinical outcomes of various carcinomas: a systematic review and meta-analysis. BMC Cancer 2014;14:819.

29. Tierney JF, Stewart LA, Ghersi D, Burdett S, Sydes MR. Practical methods for incorporating summary time-to-event data into meta-analysis. Trials 2007;8:16.

30. Wang Y, Zeng T. Response to: practical methods for incorporating summary time-to-event data into meta-analysis. Trials 2013;14:391.

31. Xie Y, Chen L, Ma X, Li H, Gu L, Gao Y, et al. Prognostic and clinicopathological role of high ki-67 expression in patients with renal cell carcinoma: a systematic review and meta-analysis. Sci Rep 2017;7:44281. 
32. DerSimonian R, Laird N. Meta-analysis in clinical trials. Control Clin Trials 1986;7:177-88.

33. Yuan C, Wang C, Liu X, Kong B. Analyze association of the progesterone receptor gene polymorphism progins with ovarian cancer risk. Mol Biol Rep 2013;40:6001-10.

34. Yuan C, Liu X, Yan S, Wang C, Kong B. Analyzing association of the xrcc3 gene polymorphism with ovarian cancer risk. Biomed Res Int 2014;2014:648137.

35. Egger M, Davey Smith G, Schneider M, Minder C. Bias in meta-analysis detected by a simple, graphical test. Br Med J 1997;315:629-34.

36. Steffensen KD, Waldstrom M, Brandslund I, Lund B, Sorensen SM, Petzold M, et al. Identification of high-risk patients by human epididymis protein 4 levels during follow-up of ovarian cancer. Oncol Lett 2016;11:3967-74.
37. Scaletta G, Plotti F, Luvero D, Capriglione S, Montera R, Miranda A, et al. The role of novel biomarker he4 in the diagnosis, prognosis and follow-up of ovarian cancer: a systematic review. Expert Rev Anticancer Ther 2017;17:827-39.

38. Lee YC, Huang CC, Lin DY, Chang WC, Lee KH. Overexpression of centromere protein $\mathrm{k}$ (cenpk) in ovarian cancer is correlated with poor patient survival and associated with predictive and prognostic relevance. PeerJ 2015;3:e1386.

39. Montagnana M, Benati M, Danese E. Circulating biomarkers in epithelial ovarian cancer diagnosis: from present to future perspective. Ann Transl Med 2017;5:276.

40. Mandilaras V, Vernon M, Meryet-Figuiere M, Karakasis K, Lambert B, Poulain L, et al. Updates and current challenges in microrna research for personalized medicine in ovarian cancer. Expert Opin Biol Ther 2017;17:927-43. 